\title{
Adaptation of Chinese and German maize-based food-feed-energy systems to limited phosphate resources - a new Sino-German international research training group
}

\author{
Torsten MÜLLER (凶) ${ }^{1}$, Fusuo ZHANG ${ }^{2}$ \\ 1 Fertilization and Soil Matter Dynamics, Institute of Crop Science (340i), University of Hohenheim, 70593 Stuttgart, Germany \\ 2 College of Resources and Environmental Science, Department of Plant Nutrition, China Agricultural University, Beijing 100193, China
}

\begin{abstract}
Phosphate is supplied to agriculture by mining and fertilizer production, followed by different steps of phosphate utilization, including primary production, feed and food consumption, and conversion of biomass, with accumulation in soils, but little recycling and severe environmental losses. Phosphate is a limited essential nutrient, however, with very uneven distribution worldwide. Closing the cycle and reducing primary phosphate consumption are fundamental future challenges. Maize has a relatively high phosphate requirement. China and Germany together cover the whole range of maize production systems. The new Sino-German international research training group "Adaptation of Chinese and German maize-based food-feed-energy systems to limited phosphate resources" (AMAIZE-P) was initiated in 2018 as a joint venture of the China Agricultural University (Beijing, China) and the University of Hohenheim (Stuttgart, Germany). The interdisciplinary and complementary research is driven by the hypothesis that under phosphate limited conditions, high productivity and high phosphate use efficiency can be achieved simultaneously by adapting phosphate cycling and availability (sources) to the multipurpose phosphate demands (sinks) in maizebased food-feed-energy systems. The educational program for doctoral researchers in China and Germany includes joint block seminars, thematic field trips, case studies, methodological courses, doctoral researchers' conferences, intercultural training sessions and personal training.
\end{abstract}

Keywords international research training group, limited resources, maize, phosphate

Received April 26, 2019; accepted August 16, 2019

Correspondence: torsten.mueller@uni-hohenheim.de

\section{Phosphorus}

Phosphorus (P), usually occurring as ortho-phosphate, is a nutritional element essential for humans, animals and plants. However, two considerable challenges are not yet sufficiently addressed: environmental pollution and global resource limitation. At first, solutions to these challenges seem to be easy as both simply call for a reduction in the use of phosphate resources. However, this simple approach does not take into consideration that current phosphate use is rather inefficient, with open cycles, and that closing these cycles is an important strategy for both reducing environmental pollution and saving limited phosphate resources. In addition, the spatial distribution of the application of phosphate-containing fertilizers is extremely uneven. The closing of cycles must, therefore, include a spatial redistribution as an additional challenge. As an overall hypothesis for future work, we propose that both the environmental problems and the exhaustion of global phosphate reserves can be avoided by optimizing foodfeed-energy production and consumption systems towards low but highly efficient phosphate input and closed cycles with a maximized phosphate return.

Two major environmental risks are related to phosphate fertilization. The first major risk is that large amounts of phosphate are currently released into the environment in a non-reversible diffuse distribution contributing severely to the eutrophication of water bodies. Steffen et al. ${ }^{[1]}$ even postulated that the current annual phosphate use worldwide exceeds planetary boundaries. Reasons are related either to overuse of phosphate containing organic fertilizers and feed phosphate in areas with intensive animal husbandry and biogas production or to overuse of mineral phosphate fertilizers in intensive cropping, particularly in horticulture and speciality crop production, both with the risk of surface runoff and groundwater contamination. Germany is characterized by a strong maldistribution of phosphate 
resulting in high fertilizer surpluses in areas with high livestock and biogas plant densities and in contrast underfertilization in intensive cropping areas ${ }^{[2]}$. At the same time, large amounts of phosphate contained in sewage sludge and kitchen waste are not reused for primary production, but dumped either directly or as ash after incineration. The large recycling potential for phosphate is evident when we compare the German demand for mineral phosphate fertilizer of $153 \mathrm{kt} \cdot \mathrm{yr}^{-1} \mathrm{P}$, after subtraction of already utilized organic fertilizers, with phosphate in sewage sludge $\left(50-60 \mathrm{kt} \cdot \mathrm{yr}^{-1} \mathrm{P}\right)$ and other waste materials (at least another $70-80 \mathrm{kt} \cdot \mathrm{yr}^{-1} \mathrm{P}$ ), of which only a small proportion is currently recycled ${ }^{[2,3]}$.

Bai et al. ${ }^{[4]}$ estimated changes in $\mathrm{P}$ use and losses in the food chain of China for 1950-2010. In the manure chain, more than $50 \%$ of excreted phosphate is lost to the environment. The greatest losses are due to direct discharge of manure into water bodies or landfill. The current flow of phosphate can therefore be characterized as an open cycle where phosphate is supplied by mining, and fertilizer and food/feed additive production followed by different pathways of phosphate utilization including primary production, animal feed, human food and conversion of biomass to energy and raw materials with severe losses into the environment (Fig. 1(a)).

Therefore, maintenance- and demand-oriented recycling of phosphate resources have been identified as the most pressing future challenges for sustainable food, feed and biomass production ${ }^{[5-7]}$. Chinese scenario analyses for the year 2020 suggest that necessary reductions of fertilizer use and nutrient losses can be achieved through a combination of prohibiting manure discharge, improving manure collection and storage infrastructures, and improving manure application to cropland ${ }^{[4]}$.

One of the major future issues will be enabling the transport from nutrient surplus areas with intensive animal husbandry and biogas production to nutrient demanding farming areas. As a prerequisite, further processing is going to be a necessary practice to reduce transport costs and to design fertilizers with suitable nutrient compositions including phosphate. However, the recovery efficiency and plant availability of phosphate differs considerably between the resulting recycling fertilizers ${ }^{[8]}$.

The second major risk is that depending on their origin and processing level, mineral phosphate fertilizers and byproducts of fertilizer production may contain considerable amounts of heavy metals and even radioactive elements (uranium), which represents a second environmental risk related to phosphate fertilization ${ }^{[9]}$. In addition, phosphate containing organic fertilizers may also contain heavy metals, depending on livestock diet and building materials used for animal housing. Heavy metals in phosphate-containing recycled fertilizer may become an increasing problem, depending on the source materials and subsequent processing methods. Purification, however, is energy consuming and technologically demanding and, therefore, only feasible if phosphate fertilizer prices are sufficiently high.

Of all nutrients essential for plants and animals, phosphate is one of the most limited worldwide. Based on recent stock estimates and assuming continued recent rates of consumption, phosphate rock reserves for the production of fertilizer and feed phosphates will be available for the next 250-300 years (based on estimations by $\mathrm{USGS}^{[10]}$ ). Although this does not indicate an imminent risk, it must additionally be considered that worldwide phosphate rock reserves are very unevenly distributed with 71\% located in Morocco and Western Sahara and only 5\% located in China ${ }^{[10]}$. Germany does not have any phosphate reserves of its own. Country credits (as an OECD country risk classification) of Morocco are estimated to be negative, indicating a considerable risk for losing access to the phosphate rock reserves due to political instability and low trustworthiness ${ }^{[11]}$. Weighted country risks (risk of investing in a country) of countries with phosphate mining and phosphate stocks recently estimated by the German Commodity Agency (Deutsche Rohstoffagentur, DERA $\left.{ }^{[12]}\right)$ are both negative $(-0.17$ and -0.30 , respectively) indicating already a moderate risk. Even more alarming are the estimated high mean country concentrations (Herfindahl-Hirschman index $\times 10.000=$ 2.537 and 4.728, respectively) which are tending to increase. In total, DERA classified phosphate between risk groups 2 and 3 (moderate and high risk, respectively) with an upwards trajectory.

Furthermore, the quality of the phosphate resources at the locations in Morocco and Western Sahara is low, often with high heavy metal contaminations, particularly cadmium, thus leading to increasing processing costs. When Morocco and Western Sahara are excluded, the life expectancy of phosphate reserves of all other phosphate mining countries is only about $70-80$ years and the life expectancy of Chinese stocks is estimated as less than 25 years when extrapolating the annual consumption (based on estimations by USGS ${ }^{[10]}$ ). Hence, there is a considerable risk that an essential production factor (phosphate) not only becomes limiting but also becomes completely unavailable, without possible substitutes. Also, imminent exhaustion of an essential agricultural production factor is a completely new obstacle from an economic point of view at the level of the farm enterprise, the region and the sector market, with a strong feedback to primary production and processing. Furthermore, exploration costs may increase considerably if accessibility and quality of the remaining resources decrease with ongoing exploitation.

Decreasing phosphate resources with increasing exploitation costs and decreasing quality of the remaining phosphate rock will further increase prices for fertilizers and feed phosphate ${ }^{[13]}$, leading to economic limitations for phosphate application, decreasing economic performance of crop production and an increasingly uneven distribution of access to phosphates. 
Previous research focused mainly on increasing the amount and quality of agricultural products and subsequent processing under the basic assumption that the supply of phosphate is market-driven, but in principle not limited. Now, this basic assumption must be changed and two demands must be met in order to maintain sustainable production of food, feed, energy and raw materials. (1) The use efficiency of fertilizer, food and feed phosphate must be maximized and losses from the system must be minimized to avoid environmental problems and to extend the lifetime of global phosphate resources. (2) As a result, the reality of a decreasing "active phosphate fraction" in production systems must be accepted, consequences must be evaluated and strategies to compensate for this depletion must be developed. It is virtually unknown how the steps within the phosphate cycle will react and interact (also with other essential nutrients) if phosphate input is increasingly reduced or even limited and demand pressure can be expected to rapidly impact on prices.

As a consequence, mineral phosphate fertilizer consumption in Germany is already decreasing. The mean phosphate application per unit agricultural land of $5.5 \mathrm{~kg} \cdot \mathrm{ha}^{-1} \mathrm{P}$ in 2017 (based on national statistical data on agricultural land and $\mathrm{P}$ fertilization obtained from statista website on April 14,2019) is by far outweighed by the mean annual removal from crop and pasture soil through intensive agriculture (e.g., $>40 \mathrm{~kg} \cdot \mathrm{ha}^{-1} \mathrm{P}$ for high yielding maiz $\left.{ }^{[14]}\right)$. Consequences include decreasing contents of plant-available phosphate in soils, exacerbated by the production of energy crops (here mainly silage maize) with complete removal of the above ground biomass $^{[15]}$. Paradoxically, excess supply of phosphate with organic fertilizers, e.g., originating from feed additives, creates environmental problems in areas of Germany with high livestock densities and energy crop production.

In China, the mean annual phosphate application per unit agricultural land in 2016 was $13 \mathrm{~kg} \cdot \mathrm{ha}^{-1} \mathrm{P}$ (based on statistical data taken from the FAOSTAT online database $\left.{ }^{[16]}\right)$. However, this value is averaged from areas with intensive cropping including maize and very high annual application rates or even overfertilization of phosphate as reported for Chinese vegetable production ${ }^{[17]}$ and from large areas of less intensive agriculture with low phosphate application rates or without any phosphate fertilization. The same contrasting picture was found by Li et al. ${ }^{[18]}$ with lower than agronomic optimum $\mathrm{P}$ occurring in $15 \%-92 \%$ of arable land and severe risks of $\mathrm{P}$ losses into the environment in $0.3 \%-7.2 \%$ of arable land across five Chinese arable land management zones.

Accordingly, large agronomic phosphate imbalances can be found across the world's croplands ${ }^{[19]}$. In Europe, more than half of the applied phosphate is neither used nor lost but accumulated in agricultural soils ${ }^{[20,21]}$. Surface soils (A-horizon) are estimated to contain total 100 $3000 \mathrm{mg} \cdot \mathrm{kg}^{-1} \mathrm{P}$, corresponding to $130-3900 \mathrm{~kg} \cdot \mathrm{ha}^{-1} \mathrm{P}$ per
$10 \mathrm{~cm}$ (at a bulk density of $1.3 \mathrm{~g} \cdot \mathrm{cm}^{-3}$ ). Hence, soils themselves may be considerable phosphate resources, particularly where phosphate was applied excessively over long periods ${ }^{[22]}$.

However, only a tiny fraction of the soil phosphate is present in the soil solution in a readily plant available form. This fraction is in an equilibrium with several less mobile inorganic and organic phosphate fractions whose composition and turnover strongly depends on other soil conditions ${ }^{[23]}$. Any applied phosphate, even in a water-soluble form, will rapidly take part in this exchange, with the result that it becomes immobilized in those fractions typical for the actual soil conditions. As a result, phosphate is highly immobile with very low effective diffusion coefficients in soil $^{[24]}$ and soil phosphate mobilization is a key requirement for the implementation of cropping systems under low phosphate conditions.

Plants may invest substantial parts of their photosynthetic carbon production to access soil phosphate through active phosphate mobilization from less soluble, even nonsoluble, fractions ${ }^{[25]}$. Highly phosphate-efficient maize genotypes with a high soil phosphate mobilization potential in combination with specific management and fertilization practices such as phosphate placement in the rooting zone, phosphate-mobilising bioeffectors and potentially P-mobilizing legumes in rotation or intercropped are promising to increase fertilizer phosphate uptake and use efficiency. Combining phosphate with ammonium fertilizer placement and bioeffectors particularly in high $\mathrm{pH}$ soils may be an additional strategy ${ }^{[26-28]}$.

\section{Maize-based food-feed-energy systems}

For several reasons, maize-based food-feed-energy systems are ideal reference systems for studying the consequences of reduced phosphate input and limited access to phosphate stocks under demand-driven price effects: (1) Maize is one of the most important and strongly expanding agricultural crops worldwide, having the potential for genetic adaptation to a wide climatic range. (2) Maize is a multi-purpose crop representing different elements in human nutrition (grain, oil and sweet maize), animal feed (grain and silage) and bio-energy/biomass production (silage, and grain to some extent). (3) Compared to other cereals, maize has a relatively high phosphate demand and a high sensitivity to phosphatedeficiency, particularly in the early growth stage. Due to the row spacing (up to $75 \mathrm{~cm}$ ) and slow root growth of maize, the supply of phosphate is a critical factor, particularly during seedling establishment and early development.

Below ground placement of ammonium-phosphate fertilizer is one common strategy to overcome this problem $^{[29]}$. Genetic variation in phosphate use efficiency of modern elite maize genotypes and older cultivars 
provides the potential for breeding towards highly phosphate-efficient maize genotypes when combined with below ground placement of ammonium phosphate based fertilizers ${ }^{[30]}$.

Phytate and other inositolphosphates have an important role because they represent both the main storage form of phosphate in plants, particular in seeds (maize grains), with a low digestibility for humans and non-ruminant animals and are the main highly recalcitrant organic fraction of soil phosphate. The phosphate efficiency of agronomic systems may be increased by lowering the amount of total organic phosphate in grain harvested in low phytate agricultural systems $^{[31]}$.

In animal feeding, feed phosphates are used as supplements in order to fulfill the animal's requirement. Maize-based diets for pigs and poultry especially require supplementation as the total phosphate content in maize is lower than in other cereal grains and phosphate is less available due to its presence primarily as phytate and the low activity of phytases in maize grain. In human nutrition, however, excess uptake of phosphate as a food additive is the major problem as opposed to phosphate-deficiency ${ }^{[32]}$. The content and availability of essential micronutrients in vegetable food is highly affected by the crop's phosphate nutrition and these micronutrients are often critical and limiting for human nutrition.

\section{The research approach}

Some promising steps focusing on individual aspects of phosphate limitation have been undertaken including research on increased plant phosphate efficiency (e.g., Vance \& $\mathrm{Chiou}^{[33]}$ ), fertilizer phosphate efficiency and plant availability of soil phosphate (e.g., Björkman \& Reiners ${ }^{[34]}$ ), feed phosphate availability ${ }^{[35]}$ and phosphate recycling (e.g., the recent review of Möller et al. ${ }^{[8]}$ ). Future research should, therefore, be driven by the hypothesis that under phosphate-limited conditions, high productivity and high phosphate use efficiency can be achieved simultaneously by adapting phosphate cycling and phosphate availability (sources) to the multipurpose phosphate demands (sinks) in maize-based food-feed-energy systems. Here, high productivity relates to both product quantity and product quality. Phosphate availability relates to plant uptake from soil and fertilizers and to digestibility in food and feed. Phosphate cycling relates to internal cycling by return of residues from plant and animal production, as well as to recycling at a larger scale including processing of biomass and residues (Fig. 1(b)). This is in full accordance with the $5 \mathrm{R}$ stewardship proposed by Withers et al. ${ }^{[21]}$, viz., "Re-align $\mathrm{P}$ inputs, Reduce $\mathrm{P}$ losses, Recycle $\mathrm{P}$ in bioresources, Recover P in wastes, and Redefine P in food systems". An interdisciplinary approach, including economics, is required for a thorough understanding of the whole range of potential interactions at different levels and scales, which will be used as a basis for the development and evaluation of pathways for alternative strategies.

Biological diversity in crop rotations, particularly the introduction of phosphate mobilizing legumes as main or cover crops, is considered as one of the strategies to increase phosphate availability in soils and fertilizer efficiency. Although this is not a strategy to replace phosphate taken up from the soil, it might help in utilizing phosphate accumulated in soil and keeping soil phosphate mobile under low phosphate conditions. Therefore, the investigation of maize-based cropping systems must include other crops complementing maize in a crop rotation. Specific focus should be on legumes (grain, fodder and green manure) with a high P-mobilization potential. Although P-mobilizing effects of legumes, particularly as cover crops, are well investigated and positive effects on other crops in the crop rotation have been postulated, these effects are still rather inconsistent, calling for further investigations to identify limiting factors (e.g., Pavinato et al. ${ }^{[36]}$ ). Intercropping of maize with grain legumes might be another promising option ${ }^{[37]}$.

To address this hypothesis, the Sino-German international research training group "Adaptation of Chinese and German maize-based food-feed-energy systems to limited phosphate resources" (AMAIZE- $\mathrm{P}^{[38]}$ ) was initiated in October 2018 as a joint venture of the China Agricultural University (CAU, Beijing, China) and the University of Hohenheim (UHOH, Stuttgart, Germany). China and Germany represent different but complementary maizebased food-feed-energy systems, particularly under conditions of limited P-resources (Fig. 2). Furthermore, with Germany and China as research partners, a large variety of climatic conditions and climate gradients can be covered.

To gain the deeper understanding required for the development of strategies to adapt food-feed-energy systems to phosphate limitations, research in AMAIZE-P is subdivided into four research areas with a total of 13 research subjects (Table 1). Each research subject is complementary and represented by at least one Chinese and one German senior scientist and one Chinese and one German doctoral researcher (PhD student). Research area 1 focuses on the genetic potential of maize genotypes and their ability to adapt to limited phosphate supply from different points of view (e.g., phosphate acquisition by adaptation of root morphology and rhizosphere processes, carbon allocation related to phosphate metabolism ${ }^{[39,40]}$, including changing environmental conditions). The reduction of poorly digestible, organically bound phosphates (e.g., low phytate and high phytase maize) represents specific foci. Research in this area is largely based on molecular methods.

Research area 2 moves the focus from the genetic potential to maize cultivation under limited phosphate supply at the field scale. The genetic potential can only be exploited if soil phosphate is available in a mobile or potentially mobilizable form. Beside the investigation of 
(a)

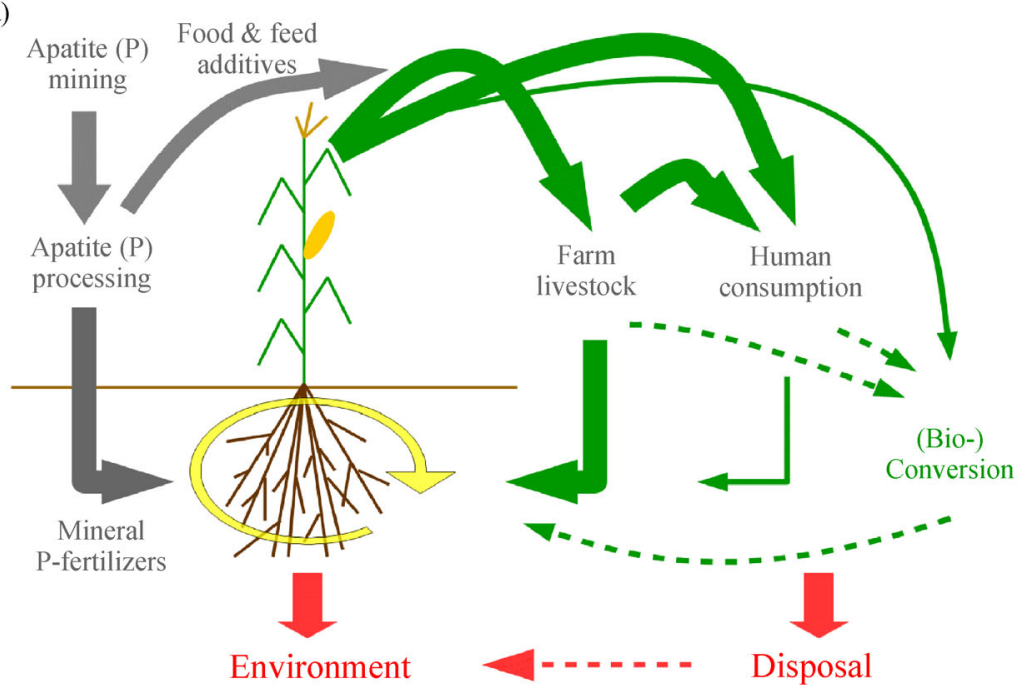

(b)

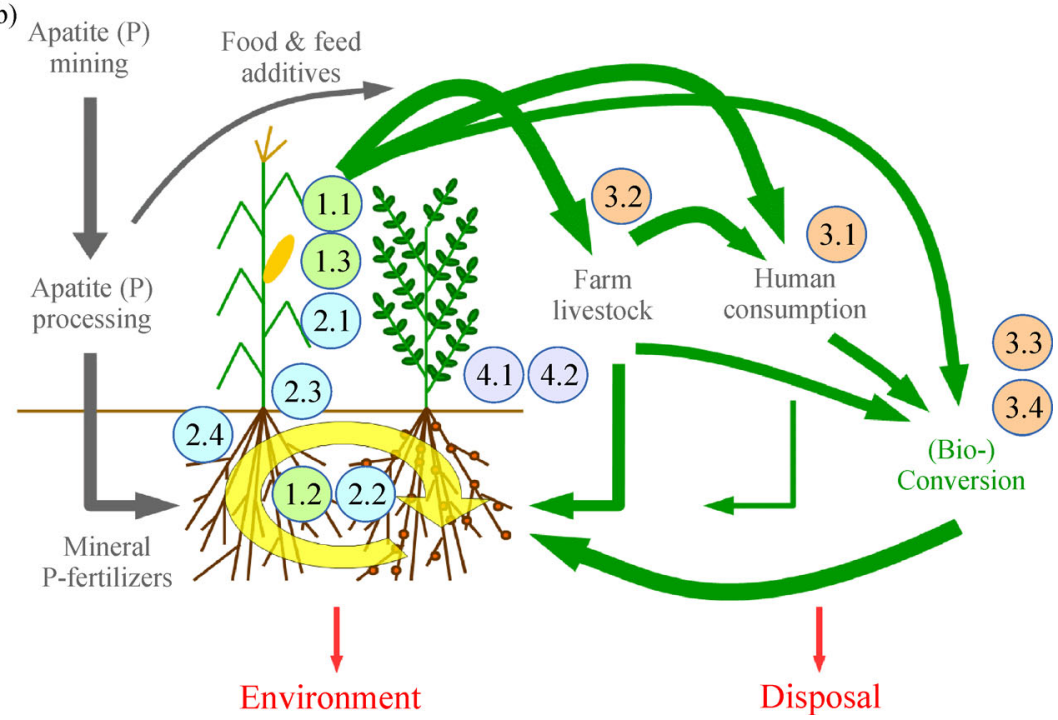

Fig. 1 The phosphate cycle today and in a future scenario with maximized phosphate use efficiency and minimized losses. Numbers in the future scenario refer to the research subjects described in Table 1. (a) Today; (b) future.

phosphate related yield and quality traits, the characterization of soil phosphate availability, chemical speciation and mobilization by biological and chemical rhizosphere processes at different scales may be addressed as major foci and prerequisites for smart farming strategies. The latter strongly depend on the characterization of the phosphate status in soil and in maize canopies with a high spatial resolution. Also, within this context, phytate must be considered as a substantial recalcitrant component of organic soil phosphate, which can amount to more than $50 \%$ of total soil phosphate. To ensure sustainability, mineral phosphate fertilizers and organic phosphatecontaining fertilizers will be considered as potential carriers of heavy metals and radioactive elements within this research area.
Research area 3 further explores the maize-based foodfeed-energy systems under conditions of limited phosphate in the areas of the final product and its utilization in human and animal nutrition as well as for the conversion of biomass into energy and raw materials. The maize grain phytate content and digestibility are considered as key limiting-factors in animal nutrition, whereas the main issue for human nutrition is the relationship between the contents of phytate and essential micronutrients. Phosphate and thus phytate limitations in biogas substrates and their interaction with microbial micronutrients are a scientific black box so far. Particularly if the enormous quantities of whole crop biomass are used for conversion into energy, the return of phosphates in biogas fermentation effluents to agriculture is crucial for the development of sustainable 


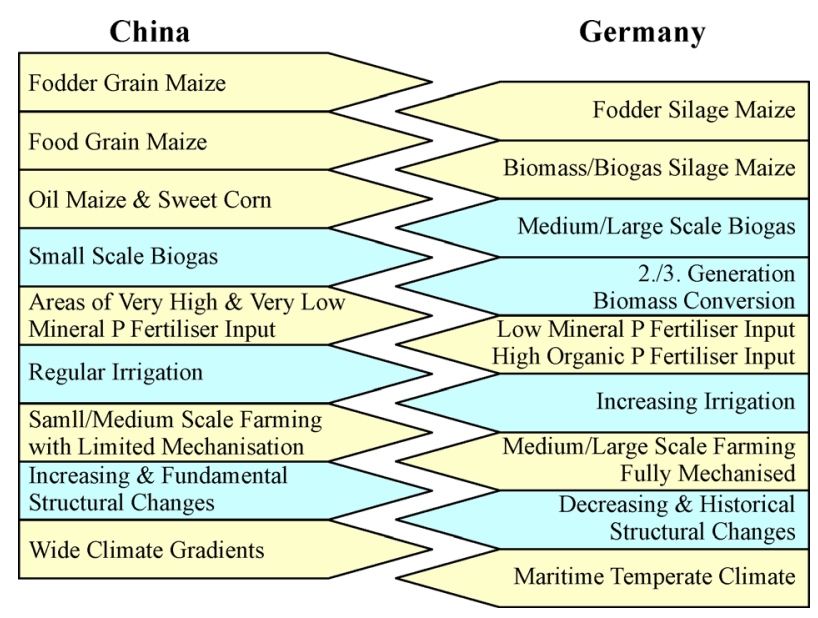

Fig. 2 Maize-based agricultural food-feed-energy systems in China and Germany together represent all aspects of maize production in contrasting and complementing situations.

future agricultural systems, providing a close link to research area 2. Second and third generation technologies of conversion of biomass are, in this sense, particularly important, because they open the way to phosphatecontaining recycled fertilizers that are analogous to existing mineral phosphate-fertilizers by simultaneously producing carbon based products for different applications. Phosphate recycling from human waste and household waste water is an integrated part of sustainable food-feedenergy systems. Phosphate recovery from sewage sludge and animal manure is furthermore addressed by cooperating projects. This includes incineration and separation products such as Struvite. Methodological cooperation is required between the first three subject areas in terms of microbiological, biochemical and energetic aspects.

Any innovation is only applicable if it produces a social and/or economic benefit and if market developments are taken into account. Consequently, research area 4 must include an economic evaluation conducted at the level of plot, farm, region and sector, including market effects. This leads to a synthesis in cooperation with all other subject areas for the development of scenarios of sustainable maize-based food-feed-energy systems under limited phosphate conditions.

\section{Qualification program for doctoral researchers}

The qualification program is a further development of wellestablished and successful structures derived from a former international research training group (GRK 1070, German Research Foundation). The qualification program is mainly based on six specific educational instruments for each doctoral researcher cohort:

(1) Five joint Sino-German block seminars (two in Germany in spring, three in China in autumn) are the core element of the educational program where participants and supervisors from China and Germany come together. The joint Sino-German leadership rotates between the participating researchers. Each block seminar consists of two parts: (a) The first part is dominated by presentations and discussions of the research progress of each doctoral researcher. (b) The second part of each block seminar has an individual thematic or methodological focus related to the research subjects of AMAIZE-P, where invited international experts give lectures and workshops, and/or conduct exercises. In addition, there is an introduction to scientific writing. Beside this structured program, there are usually several spontaneous and planned activities such as issue-related discussions, planning meetings and lab visits, typically involving the invited experts. As already experienced in the GRK 1070, the joint block seminars

Table 1 Project structure

Subject area

1 Genetic potential

2 Management at field and farm level

3 Nutrition and recovery

4 Economic evaluation and synthesis

\section{Research subject}

1.1 Genetic variation, genetic architecture and genomic prediction of phosphate-use-efficiency traits in European and Chinese maize

1.2 Importance of root architecture and rhizosphere-related processes for improving phosphate use efficiency

1.3 Regulatory modules of carbon resource allocation under different phosphate availabilities

2.1 Genotype to phenotype modelling of phosphate acquisition and related yield and quality traits of maize

2.2 Increasing soil phosphate availability and phosphate fertilizer efficiency

2.3 Detecting phosphate status in soil and in maize canopies by non-invasive methods

2.4 Heavy metals from phosphate fertilizers in maize-based food-feed-energy systems

3.1 The impact of reduced phosphate-availability on essential micronutrients in maize for human consumption

3.2 Inositol phosphates in the digestive tract and phosphate utilisation of farm animals fed maize

3.3 Deployment of phosphate resources for nutrient recycling via anaerobic digestion systems

3.4 Hydrothermal conversion of biomass to carbon materials with phosphate recovery

4.1 Economic analyses at plot, farm enterprise, regional and sectoral levels

4.2 Synthesis and field experiments 
will serve as the common think tank for the whole project. A particular aim of the block seminars is to widen the perspective of doctoral researchers to an interdisciplinary view starting from their own field of expertise.

(2) Thematic field trips are held after each block seminar. The field trips bring the doctoral researchers to different areas in China and Germany that exemplify and illustrate the issues discussed in the respective block seminars.

(3) Two case studies (pre-prepared, one in China and one in Germany) are conducted in the first and second year of each doctoral researcher generation in combination with two of the thematic field trips. Here, the doctoral researchers get an in-depth on-site understanding of a specific problem related to the subject of AMAIZE-P followed by an interdisciplinary exercise with the aim of developing reliable solutions in group work and to present these solutions in a debriefing seminar.

(4) An international scientific doctoral researcher conference is jointly organized in the third year of each doctoral researcher generation. In addition to contributions from the doctoral researchers' own research, related external contributions are a substantial part of this activity. The conference replaces one block seminar in the third year.

(5) As an important part of their training activities, German and Chinese doctoral and postdoctoral researchers usually work for three months each year in their partner country. German and Chinese doctoral/postdoctoral counterparts of a given research subject cooperate and support each other in their daily work and closely interact with respect to the strategic development of their scientific topic. Research visits are typically hold immediately before or concurrently with the block seminars. Extraordinary stays may be necessary in connection with field experiments.

(6) A comprehensive intercultural training, including improvement of personal skills regarding foreign language proficiency and intercultural communication will be provided for all doctoral researchers.

For most research subjects, early career researchers participate as co-supervisors, both from $\mathrm{UHOH}$ and CAU. Early career researchers and other doctoral researchers in particular from cooperating projects of the two participating universities are invited to take part in the activities under the qualification program.

All doctoral researchers may take part in additional educational programs. This includes generic professional skills trainings, language courses, computer and software courses, with this training giving the doctoral researchers a strong start into their professional career.

After successful completion of the qualification program, the doctoral researchers are prepared to work in science and development or related areas both in the public and in the private sector, particularly in an international Asian context. They will also be qualified to work in administrative positions where profound scientific knowledge and understanding is a prerequisite.

Acknowledgements This work was funded by the Deutsche Forschungsgemeinschaft (DFG, German Research Foundation) - 328017493/GRK 2366 (International Research Training Group "Adaptation of maize-based foodfeed-energy systems to limited phosphate resources") and by the China Agricultural University. We thank all principle investigators of the GRK 2366 for their valuable contributions. We thank the reviewers and in particular Ian Riley for their helpful remarks.

Compliance with ethics guidelines Torsten Müller and Fusuo Zhang declare that they have no conflicts of interest or financial conflicts to disclose.

All applicable institutional and national guidelines for the care and use of animals were followed.

\section{References}

1. Steffen W, Richardson K, Rockström J, Cornell S E, Fetzer I, Bennett E M, Biggs R, Carpenter S R, de Vries W, de Wit C A, Folke C, Gerten D, Heinke J, Mace G M, Persson L M, Ramanathan V, Reyers B, Sörlin S. Planetary boundaries: guiding human development on a changing planet. Science, 2015, 347(6223): 1259855

2. Wiesler F, Hund-Rinke K, Gäth S, George E, Greef J M, Hölzle L E, Holz F, Hülsbergen K J, Pfeil R, Severin K, Frede H G, Blum B, Schenkel H, Horst W, Dittert K, Ebertseder T, Osterburg B, Philipp W, Pietsch M. Application of organic fertilizers and organic residues in agriculture. Berlin: Scientific Board for Fertilization of the German Federal Ministry of Food and Agriculture, 2015 (in German)

3. Fricke K, Bidlingmaier W. Phosphorus potential in high value organic municipal waste and its application. In: Proceedings of the UBA \& ISA Phosphorus Conference Recycling of Phosphorus from Waste Water and Waste in Agriculture, Berlin. Aachen, Germany: Society for the Promotion of the Institute for Urban Water Management, 2003, 9/1-9/15 (in German)

4. Bai Z, Ma L, Ma W, Qin W, Velthof G L, Oenema O, Zhang F. Changes in phosphorus use and losses in the food chain of China during 1950-2010 and forecasts for 2030. Nutrient Cycling in Agroecosystems, 2016, 104(3): 361-372

5. Childers D L, Corman J, Edwards M, Elser J J. Sustainability challenges of phosphorus and food: solutions from closing the human phosphorus cycle. Bioscience, 2011, 61(2): 117-124

6. Gross M. Fears over phosphorus supplies. Current Biology, 2010, 20(9): 386-387

7. Neset T S, Cordell D. Global phosphorus scarcity: identifying synergies for a sustainable future. Journal of the Science of Food and Agriculture, 2012, 92(1): 2-6

8. Möller K, Oberson A, Bünemann E K, Cooper J, Friedel J K, Glæsner N, Hörtenhuber S, Løes A K, Mäder P, Meyer G, Müller T, Symanczik S, Weissengruber L, Wollmann I, Magid J. Improved phosphorus cycling in organic farming: navigating between constraints. Advances in Agronomy, 2018, 147: 159-237

9. Taylor M, Kim N, Smidt G, Busby C, McNally S, Robinson B, Kratz S, Schnug E. Trace element contaminants and radioactivity 
from phosphate fertilisers. In: Schnug E, De Kok L J, eds. Phosphorus in agriculture: 100\% zero. Dodrecht: Springer, 2016, 231-266

10. Anonymous. Mineral commodity summaries. Reston, USA: U.S. Geological Survey, 2019

11. Killiches F, Gebauer H P, Franken G, Röhling S, Schulz P, Müller H W. Phosphate. Hannover, Germany: German Federal Institute for Geosciences and Natural Resources (BGR), 2013 (in German)

12. Brandenburg T, Buchholz P, Dorner U, Huy D, Liedtke M, Schmidt M, Sievers H, Homberg-Heumann D, Lang K, Schumacher A, Wehenpohl B. DERA natural recource information. Berlin: German Resource Agency (DERA) at the German Federal Institute for Geosciences and Natural Resources (BGR), 2016 (in German)

13. Cordell D, Drangert J O, White S. The story of phosphorus: global food security and food for thought. Global Environmental Change, 2009, 19(2): 292-305

14. Knittel H, Albert E, Ebertseder T. Practical handbook fertilizers and fertilization. Bergen/Dumme: Agrimedia GmbH, 2012 (in German)

15. Zorn W, Schröter H, Heß H, Wagner S. Fertilizing energy crop rotations differently. DLG-Communication, 2011 (in German)

16. FAO. Statistical data. Available at FAO website on April 14, 2019

17. Yan Z, Liu P, Li Y, Ma L, Alva A, Dou Z, Chen Q, Zhang F. Phosphorus in China's intensive vegetable production systems: overfertilization, soil enrichment, and environmental implications. Journal of Environmental Quality, 2013, 42(4): 982-989

18. Li H, Liu J, Li G, Shen J, Bergström L, Zhang F. Past, present, and future use of phosphorus in Chinese agriculture and its influence on phosphorus losses. Ambio, 2015, 44(Suppl 2): 274-285

19. MacDonald G K, Bennett E M, Potter P A, Ramankutty N. Agronomic phosphorus imbalances across the world's croplands. Proceedings of the National Academy of Sciences of the United States of America, 2011, 108(7): 3086-3091

20. Ott C, Rechberger H. The European phosphorus balance. Resources, Conservation and Recycling, 2012, 60: 159-172

21. Withers P J A, van Dijk K C, Neset T S S, Nesme T, Oenema O, Rubæk G H, Schoumans O F, Smit B, Pellerin S. Stewardship to tackle global phosphorus inefficiency: the case of Europe. Ambio, 2015, 44(Suppl 2): 193-206

22. Sattari S Z, Bouwman A F, Giller K E, van Ittersum M K. Residual soil phosphorus as the missing piece in the global phosphorus crisis puzzle. Proceedings of the National Academy of Sciences of the United States of America, 2012, 109(16): 6348-6353

23. Shen J, Yuan L, Zhang J, Li H, Bai Z, Chen X, Zhang W, Zhang F. Phosphorus dynamics: from soil to plant. Plant Physiology, 2011, 156(3): 997-1005

24. Barber S A. Soil nutrient bioavailability. A mechanistic approach. 2nd ed. John Wiley and Sons Ltd., 1995

25. Lambers H, Finnegan P M, Laliberté E, Pearse S J, Ryan M H, Shane M W, Veneklaas E J. Phosphorus nutrition of Proteaceae in severely ohosphorus-impoverished soils: are there lessons to be learned for future crops? Plant Physiology, 2011, 156(3): 10581066

26. Nkebiwe P M, Weinmann M, Müller T. Improving fertilizer-depot exploitation and maize growth by inoculation with plant growthpromoting bacteria-from lab to field. Chemical and Biological Technologies in Agriculture, 2016: 15

27. Nkebiwe P M, Weinmann M, Bar-Tal A, Muller T. Fertilizer placement to improve crop nutrient acquisition and yield: a review and meta-analysis. Field Crops Research, 2016, 196: 389-401

28. Nkebiwe P M, Weinmann M, Müller T. Densely rooted rhizosphere hotspots induced around subsurface $\mathrm{NH}_{4}{ }^{+}$-fertilizer depots: a home for P-solubilizing PGPMs? Chemical and Biological Technologies in Agriculture, 2017: 29

29. Jing J, Rui Y, Zhang F, Rengel Z, Shen J. Localized application of phosphorus and ammonium improves growth of maize seedlings by stimulating root proliferation and rhizosphere acidification. Field Crops Research, 2010, 119(2-3): 355-364

30. Shen J, Li C, Mi G, Li L, Yuan L, Jiang R, Zhang F. Maximizing root/rhizosphere efficiency to improve crop productivity and nutrient use efficiency in intensive agriculture of China. Journal of Experimental Botany, 2013, 64(5): 1181-1192

31. Rose T J, Liu L, Wissuwa M. Improving phosphorus efficiency in cereal crops: is breeding for reduced grain phosphorus concentration part of the solution? Frontiers of Plant Science, 2013, 4: 444

32. Calvo M S, Uribarri J. Public health impact of dietary phosphorus excess on bone and cardiovascular health in the general population. American Journal of Clinical Nutrition, 2013, 98(1): 6-15

33. Vance C P, Chiou T J. Phosphorus focus editorial. Plant Physiology, 2011, 156(3): 987-988

34. Björkman T, Reiners S. Application of bicarbonate to highphosphorus soils to increase plant-available phosphorus. Soil Science Society of America Journal, 2014, 78(1): 319-324

35. Metzler B U, Mosenthin R, Baumgärtel T, Rodehutscord M. The effect of dietary phosphorus and calcium level, phytase supplementation, and ileal infusion of pectin on the chemical composition and carbohydrase activity of fecal bacteria and the level of microbial metabolites in the gastrointestinal tract of pigs. Journal of Animal Science, 2008, 86(7): 1544-1555

36. Pavinato P S, Rodrigues M, Soltangheisi A, Sartor L R, Withers P J A. Effects of cover crops and phosphorus sources on maize yield, phosphorus uptake, and phosphorus use efficiency. Agronomy Journal, 2017, 109(3): 1039-1047

37. Li X F, Wang C B, Zhang W P, Wang L H, Tian X L, Yang S C, Jiang W L, Van Ruijven J, Li L. The role of complementarity and selection effects in $\mathrm{P}$ acquisition of intercropping systems. Plant and Soil, 2018, 422(1-2): 479-493

38. Müller T, Doluschitz R, Roelcke M. Sino-German International Research Training Group "Adaption of maize-based food-feedenergy systems to limited phosphate resources" (GPK 2366). Available at DFG website on August 21, 2019

39. Chapin F S III, Schulze E D, Mooney H A. The ecology and economics of storage in plants. Annual Review of Ecology and Systematics, 1990, 21(1): 423-447

40. Hermans C, Hammond J P, White P J, Verbruggen N. How do plants respond to nutrient shortage by biomass allocation? Trends in Plant Science, 2006, 11(12): 610-617 